\title{
Атомно-силовая микроскопия в решении задач реконструкции природных кристаллогенетических процессов
}

\author{
Пискунова Н.Н. ${ }^{1}$, Радаев В.А. ${ }^{1}$, Крючкова Л.С. ${ }^{2}$, Сокерина Н.В. ${ }^{1}$ \\ ${ }^{1}$ ИГ ФИЦ Коми НЦ УрО РАН, Сыктывкар, piskunova@geo.komisc.ru \\ ${ }^{2}$ Санкт-Петербургский государственный университет, C.-Петербург, 2106@list.ru
}

Аннотация. С применением метода атомно-силовой микроскопии исследована внутренняя поверхность флюидных включений в природных кристаллах горного хрусталя (м. Желанное, Приполярный Урал, Россия) и в жильном кварце (месторождение Синильга, Приполярный Урал, Россия). Показано, что только соединение in situ метода изучения модельных кристаллов с ex situ сканированием природных кристаллов позволяет использовать атомно-силовую микроскопию для реконструкции природных кристаллогенетических процессов.

Получены высокоразрешающие изображения классических дислокационных холмиков роста на внутренних стенках включений. Проведено сравнение профильных разрезов холмиков из полостей природных флюидных включений с холмиками роста и растворения из АСМ-экспериментов на модельных кристаллах. Доказано, что внутренние поверхности полостей включений кварца представляют собой поверхности роста.

С помощью ACM, показано, что на финальном этапе роста кристалла горного хрусталя (м. Желанное), в окружающей его кристаллизационной среде произошел сначала небольшой скачок температур и давлений, а затем монотонное остывание в течение длительного времени. Об этом свидетельствует форма дислокационных холмов и особенности отложения вещества на поверхности включения.

Ключевые слова: кварц, флюидные включения, условия и механизмы роста кристаллов, дислокации, атомно-силовая микроскопия.

\section{Using atomic-force microscopy studies to reconstruct natural crystallogenetic processes}

\author{
Piskunova N.N. ${ }^{1}$, Radaev V.A. ${ }^{1}$, Kruychkova L.Y. ${ }^{2}$, Sokerina N.V. ${ }^{1}$ \\ ${ }^{1}$ IG FRC Komi SC UB of RAS, Syktyvkar, piskunova@geo.komisc.ru \\ ${ }^{2}$ Saint-Petersburg State University, St. Petersburg, Russia, 2106@list.ru
}

\begin{abstract}
We studied the ex situ fluid inclusions from samples of vein quartz (Sinilga ore occurrence, Subpolar Ural, Russia), as well as several inclusions from a large rock crystal (Zhelannoe deposit, Subpolar Ural, Russia), with an atomic force microscope.

It is shown that a combination of the in situ AFM-study of model crystals and the ex situ-scanning of natural crystals offers a means for a partial reconstruction of natural crystallogenetics processes.

We obtained the high-resolution images of the flat- top hillocks on inner walls of inclusions. It is shown that these are classical dislocation growth hillocks. With the help of mathematical analysis, we compared the profiles of the inclusion hillocks with the profiles of the hillocks observed in both growth and dissolution AFM experiments.

We determined that the relief of the inner inclusion walls exactly corresponds to the growth. It was shown that the crystal (Zhelannoe depozit), after the formation of some fluid inclusions, was first subjected to a higher temperature and pressure, and then to slow cooling during a long period of time. These processes could be evidenced by the form of the dislocation hillocks and the patterns of deposition of the matter on the inner walls of the inclusions.

Key words: quartz, fluid inclusions, conditions and mechanisms of crystal growth, dislocations, atomic force microscopy.
\end{abstract}

\section{Введение}

Атомно-силовая микроскопия (АСМ), внедряемая в научные лаборатории с 90-х годов прошлого века, в настоящее время является основным инструментом для получения высокоразрешающих изображений рельефа поверхности твердых тел. При ее описании в отношении кристаллогенетических исследований все чаще употребляется приставка in-situ. Этот латинский термин означает «в том же месте» и для роста кристаллов подразумевает неразрушающий контроль во время 
протекания процесса в жидкой или газовой среде, в противовес термину ex-situ, который означает исследование после извлечения из естественной среды, дробления, химической обработки и т.д. In-situ с помощью АСМ проводятся наблюдения за процессами роста модельных кристаллов из раствора в наноразмерном, то есть практически элементарном для кристаллической ячейки, масштабе (Rashkovich et al., 2006; Vekilov, 2005; Piskunova, Rakin, 2005; Пискунова, 2007; Van Driessche et al., 2008). Опираясь на данные, полученные в таких экспериментах, исследователи стали предпринимать попытки расшифровки ростовых картин, наблюдаемых на поверхности кристаллов минералов. Реализации этой идеи с помощью АСМ долгое время препятствовала основная «проблема» природных кристаллов - внешне гладкие грани в масштабе нескольких микрометров оказывались грубо изрытыми, с крупными ступенями. Это не позволяло провести скрупулезное изучение поверхности, и тем более сложить целую картину какого-либо элементарного явления. Кроме этого, проводить параллели между поведением природных ступеней высотой в десятки микрометров и полученых на АСМ модельных ступеней высотой в десять ангстрем, некорректно. Поэтому для достижения цели данной работы мы выбрали в качестве объектов изучения внутренние поверхности флюидных включений кристаллов, предполагая, что ростовые акцессории там наноразмерные и сохранили себя в первозданном виде. Таким образом, не только раствор из включений и внешние очертания полости включений, но и тонкий рельеф стенок включений, могут нести информацию о протекавших некогда процессах.

Исследователи давно предполагали, что минерал-хозяин из флюида может со временем кристаллизоваться на стенках включения, но до вхождения в практику минералогических исследований высокоразрешающих методов, доказать это можно было только косвенными методами. Так, отмечалось, что валовый химический состав флюида синтетических включений иногда ниже исходных концентраций компонентов (Чепкая, 1997). При увеличении температуры в раствор может переходить некоторое количество кремнезема за счет растворения стенок (Перетяжко и др., 2010). Иногда отмечалось, что после прогрева «меняется рельеф поверхности вакуоли включения» (Смирнов и др., 2011).

Выделенные как отдельное направление исследований оптические наблюдения за контурами включений не имели достаточной разрешающей способности, хотя способны были зафиксировать изменение контуров включений в процессе их нагревания и охлаждения. Например, экспериментально доказано, что так называемую форму обратного кристалла, включение приобретает только после длительной выдержки в условиях, близких к равновесным, иногда после предварительного повышения температуры или давления (Pecher, 1981; Sterner, Bodnar, 1989). На полигонизацию контура включения в таких условиях, а также образование ореола малых включений вокруг большого указывается также в работе (Bodnar, Vityk, 1994).

Первое обзорное АСМ-изображение полувскрытого включения получил Боднар для альбита (Bodnar, 2003). По мнению автора, обнаруженные на стенках включений многочисленные мелкие ямки «в течение последующего роста кристаллов... вероятно, сами станут субмикроскопическими флюидными включениями». Имеются также немногочисленные свидетельства исследования внутренних стенок включений с помощью электронной микроскопии. Так в работе (Ситдикова, 2007) приведены электронно-микроскопические изображения вскрытых включений м. Тлянчи-Тамак Татарского свода, в которых имеются свидетельства перекристаллизации «с возникновением внутри включения друзовидных форм кварца».

\section{Методика исследования}

Ex-situ изучены флюидные включения из образцов жильного кварца (рудопроявление Синильга, Приполярный Урал, Россия), а также несколько включений из крупного кристалла горного хрусталя (месторождение Желанное, Приполярный Урал, Россия) (рис. 1).

Исследования проводились на оборудовании ЦКП «Геонаука» (Сыктывкар), использовался атомно-силовой микроскоп Ntegra Prima (NT-MDT, Россия) и стандартные кремниевые кантилеверы (NanoProbe, Великобритания) с радиусом закругления кончика 5 нм. После вырезания из кри- 


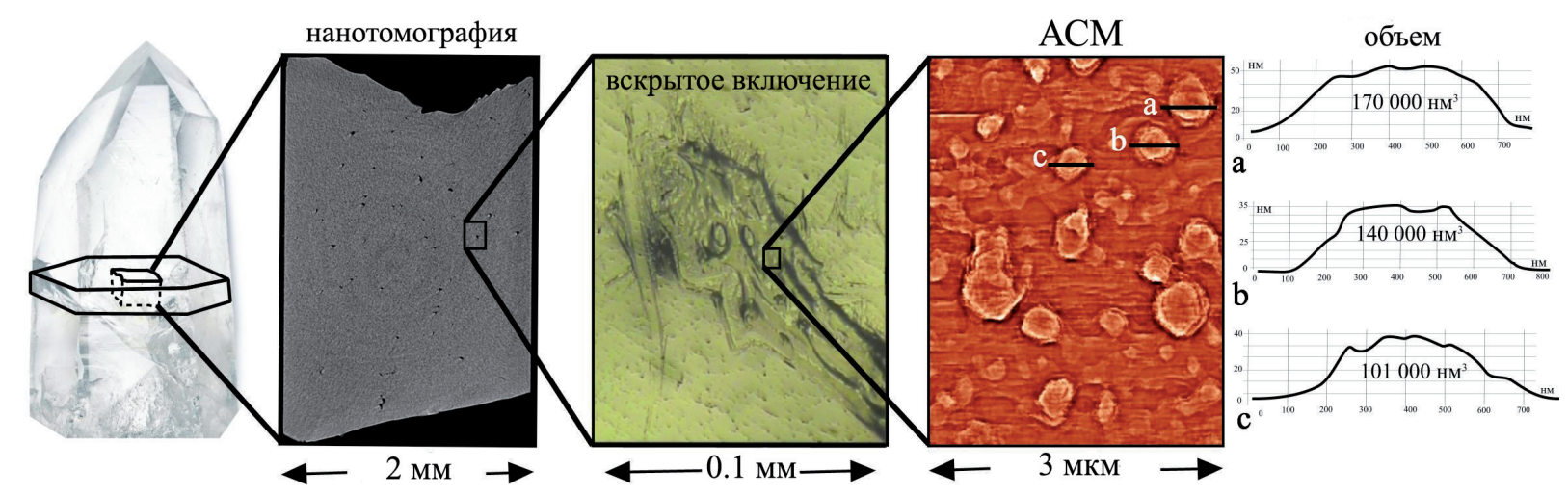

Рис. 1. Последовательные изображения, показывающие методику исследования внутренней поверхности флюидных включений в большом кристалле кварца.

Fig. 1. Sequential images showing the procedure for the study of the inner surface of the fluid inclusions in a large quartz crystal.

сталла пластинки пришлифовывались, выдерживались в ультразвуковой ванне для очистки от закристаллизованных солей и обломков. Результаты сравнивались с нашими in-situ наблюдениями процессов на модельных кристаллах, которые выращивались непосредственно в жидкостной ячейке микроскопа (Пискунова, 2007). Данные относительно объема и площади внутренней поверхности флюидных включений получены с применением нанотомографа Bruker 2011 (РЦ «Геомодель», СПбГУ, Санкт-Петербург) и использованы для определения концентрации $\mathrm{SiO}_{2}$ в маточном растворе. Она оказалась равной 2.3 г/л, это первоначальная и довольно грубая оценка.

\section{Результаты и их обсуждение}

Ранее (Пискунова, 2019) нами проведено исследование каналов дислокационных источников и показано, что скопления выходов дислокационных каналов могут являться одной из главных причин появления самих этих включений. Кроме каналов на стенках вакуолей включений нами обнаружены нано- и микроразмерные твердые включения, иногда четкой формы (рис. 2). Рельеф стенок характеризуют также многочисленные холмики роста, некоторые из них имеют выраженную спираль на вершине (рис. 3). Полученные нами с помощью атомно-силовой микроскопии факты сви-
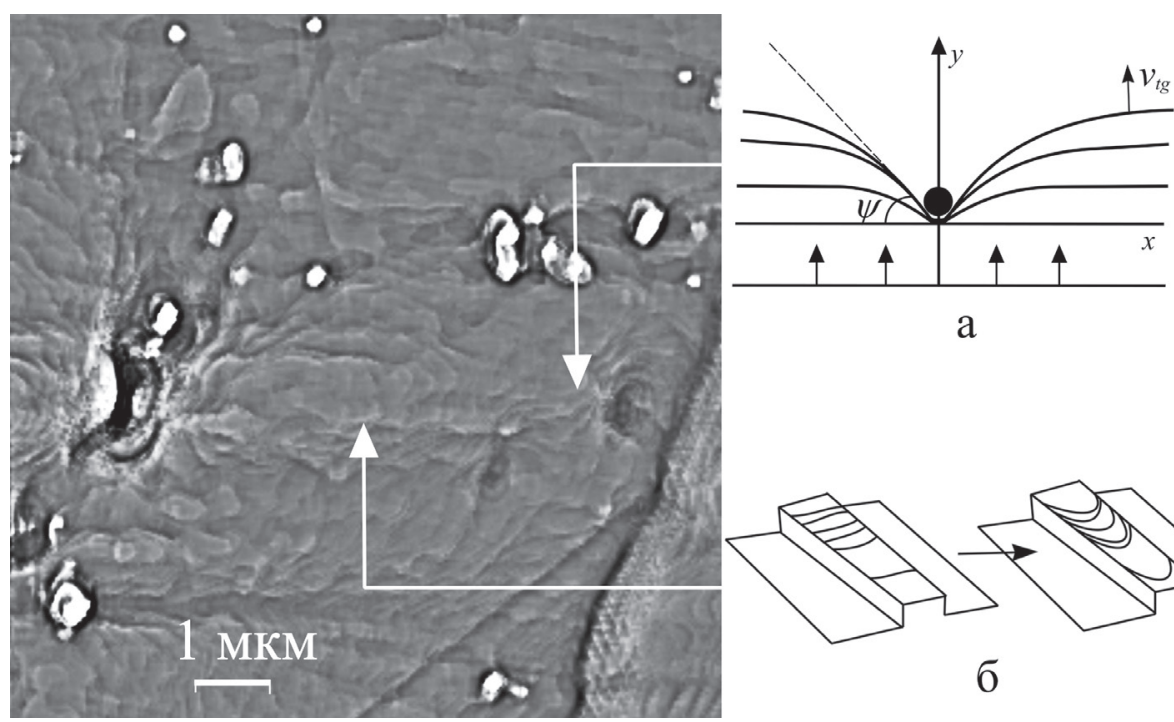

a

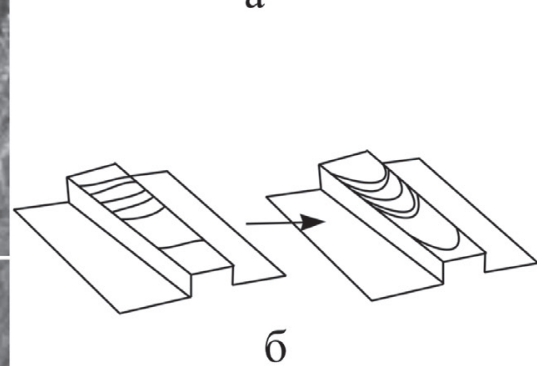

Рис. 2. Изгиб ростовых ступеней на препятствии на стенках флюидного включения: а - взаимодействие ростовых ступеней с ямками, б - прогиб ступеней при росте на гребнях

Fig. 2. Bending of growth steps front on obstacle inside inclusions of quartz rock crystal: a - interaction with pits, $\mathrm{b}$ - bending of steps on ridges. 

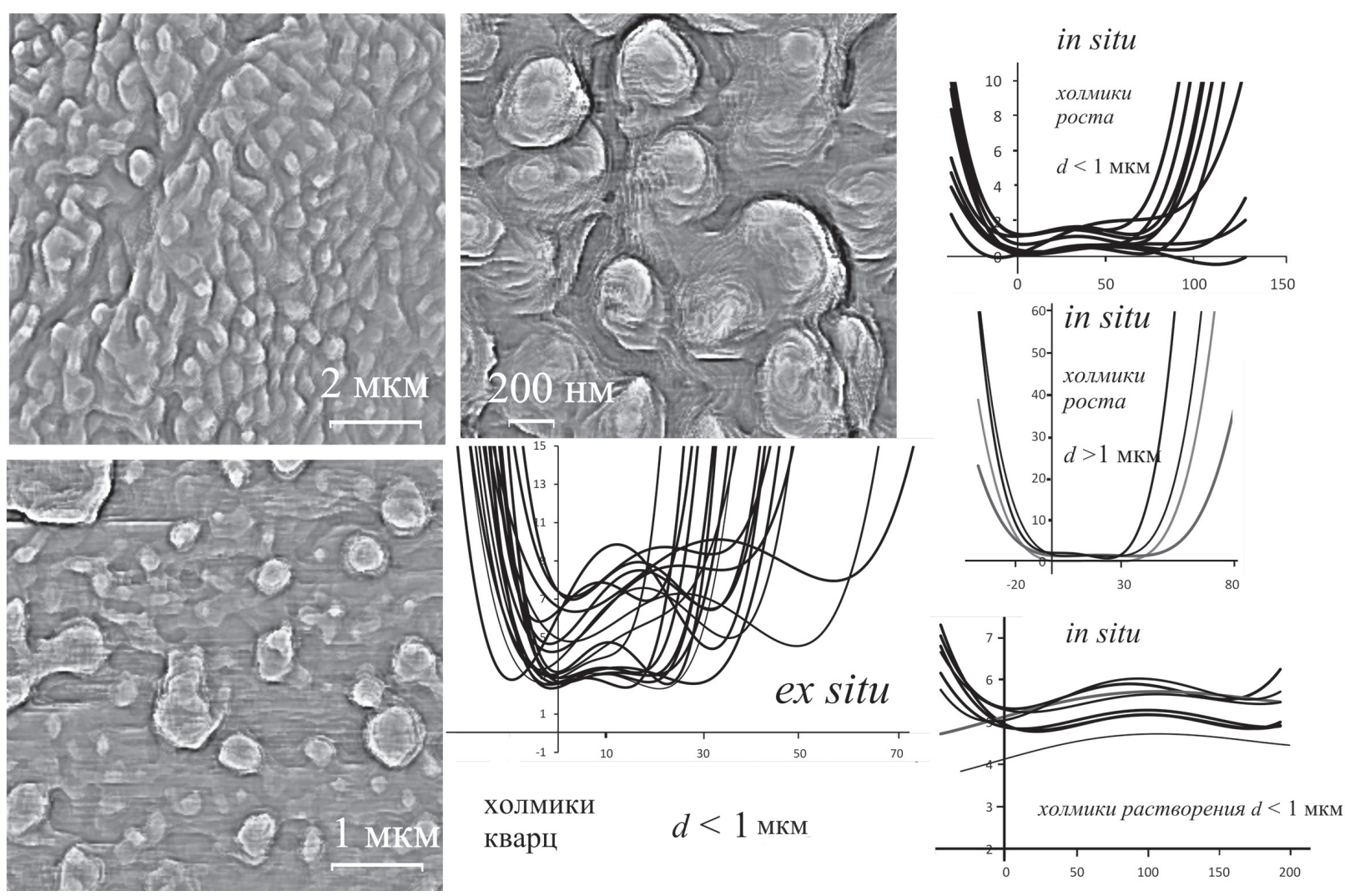

Рис. 3. Холмики роста на винтовых дислокациях на внутренних поверхностях полостей флюидных включений кварца и аппроксимирующие параболы четвертой степени, описывающие их профили. Справа - графики для растущих и растворяющихся холмиков из in situ экспериментов.

Figure 3. Growth hillocks on the inner surfaces of fluid inclusions in quartz crystal and their profile approximating fourth-degree parabola. Left part - growing and dissolving hillocks on model crystals of our in situ experiments.

детельствуют о том, что внутренняя поверхность полостей включений представляет собой поверхность роста:

1). Ступени изгибаются в непосредственной близости от выходов дислокационных каналов и твердых препятствий на поверхности (рис. 2). Взаимодействие фронта роста ступеней и препятствий на грани - распространенное явление. Если речь идет о росте и о твердых препятствиях, то очень много зависит от смачиваемости ступенями одного вещества частиц другого вещества. На «неродной» материал вещество не осаждается, вокруг твердого включения образуется область нарушения равномерного распределения вещества ступени.

Очень большую роль играют флуктуации скорости роста, при которых благодаря локальным флуктуациям плотности, возникают неравномерности в осаждении вещества. Всегда существует вероятность присоединения - отрыва, благодаря этому геометрический фронт ступени флуктуирует. Фронт с боков от препятствия выпячивается. Ступень изгибается на препятствии и тормозится (Пискунова, 2007). По схожему механизму протекает взаимодействие растущей ступени с ямками различной природы.

2). Обнаруженные нами холмики (рис. 3) являются зачатками конусовидных акцессорий роста на поверхности базиса, снятыми в наноразмерном масштабе, которые являются классическими дислокационными холмиками роста, нарастающими по известному механизму Франка. Однако ранее мы показали, что такие винтовые холмики могут быть и свидетельством растворения (Пискунова 2012). Поэтому нами были получены профильные разрезы девятнадцати холмиков из полостей флюидных включений. Затем, мы сравнили их с профилями восьми спиральных холмиков, которые в наших in-situ наблюдениях растворялись, и с теми, которые мы в разных экспериментах наблюдали растущими (десятью мелкими и четырьмя крупными). Сравнивались одинаковые по размеру 
изображения. Профили всех холмиков были аппроксимированы функциями полиномов различной степени. В широком интервале на оси абсцисс параболы четвертой степени для холмиков из включений имели вполне обозримый размах ветвей, почти такой же, как и параболы для растущих холмиков из in-situ экспериментов (рис. 3). В то же время для всех графиков растворения размах ветвей параболы был минимум в четыре раза больше.

Согласно теореме Виетта, произведение и сумма всех корней уравнения четвертой степени равны определенному отношению коэффициентов данного уравнения. Наши корреляционные расчеты показали, что наиболее точно размах параболы четвертой степени связан с произведением корней. Полученные в результате расчетов значения для флюидных включений близки к случаю роста поверхности, для растворения полученный коэффициент оказался в несколько тысяч раз больше. Само наличие холмиков на поверхности стенок включений говорит о том, что резкого температурного перехода не было, вещество успевало встраиваться в растущую поверхность, а не кристаллизовалось в растворе. Об этом же свидетельствует аккуратная достройка спиралей, следы огибания препятствий. О росте в течение долго времени при малых пересыщениях говорит то, что вещество откладывалось только на винтовые холмики, не оседая в интерстиции, и не формируя макроступеней. То есть значение пересыщение в каждый момент времени было невысоким. Данные АCM, показывает, что даже вблизи равновесия скорость тангенциального роста ступеней может достигать 2 нм/с, и при таких скоростях макроступени могут иметь преимущество. Можно предположить, что скорости роста холмиков обнаруженные внутри флюидных включений кварца месторождения Желанное, составляли первые единицы нанометров в секунду. Это значение может характеризовать также скорость снижения температуры.

Холмики почти на всех полученных изображениях расположены плотно. В стабильных условиях на поверхности грани обычно действует всего несколько холмиков, происходит поглощение одних другими из-за их конкуренции. Согласно теории дислокационного роста, высокая плотность холмиков говорит о том, что на предыдущем этапе, температура и давление претерпели значительный скачок, в результате которого произошла перестройка поверхности, и возникновение множества акцессорий роста.

По своей форме холмики, обнаруженные на некоторых участках представляют собой широкие плосковерхушечные островки. Такая форма связана с ограничением питания, что вполне естественно для замкнутой полости. Можно утверждать, что происходило медленное снижение пересыщения до минимума. Вначале, при смене условий, угловая скорость вращения спирали на самой верхушке всегда больше, спираль делает на верхушке больше оборотов, чем у подножья. Затем, когда ситуация стабилизируется, угловая скорость всех этажей спирали становится одинаковой, то есть становится одинаковым тангенс угла наклона холмика по всей высоте. Поэтому описываемые холмики кроме плоской вершины имеют округлое сечение и очень крутые боковые стенки. Наши исследования показывают, что подобная форма также может формироваться при очень медленной трансформации ямки, образованной на дислокации в холмик, образованный на той же дислокации (Пискунова, 2012). Связано это с малыми значениями пересыщения при таком переходе. Известно, что в области малых значений пересыщения зависимость его от скорости становится нелинейной, и этим объясняется немонотонность наклона для дислокационного холмика (Портнов, Чупрунов, 2010). На форму холмов влияют также примеси, Черновым была предложена нелинейная теория, описывающая наблюдаемую немонотонность, начиная с некоторого пересыщения имеющего, следовательно, смысл порогового пересыщения по отношению к действию примесей (Чернов, 1987). При этом размер примеси должен быть сравним с размером излома на ступени, то есть составлять первые единицы ангстрем.

Таким образом, такая форма некоторых из обнаруженных ростовых холмиков - плоские вершины, неразвитое подножье и крутые бока - свидетельствуют о формировании дислокационных спиралей при очень малых значениях пересыщения и значительном влиянии ангстремного размера примесей на протяжении длительного времени.

Работа выполнена при частичной финансовой поддержке РФФИ№ 19-05-00460. 


\section{Литература}

1. Перетяжко И.С., Смирнов С.З., Котельников А.Р., Котельникова З.А. Экспериментальное изучение системы $\mathrm{H}_{3} \mathrm{BO}_{3}-\mathrm{NaF}-\mathrm{SiO}_{2}-\mathrm{H}_{2} \mathrm{O}$ при $350-800^{\circ} \mathrm{C}$ И 1-2 кбар методом синтетических флюидных включений // Геология и геофизика. 2010. Т. 51 (4). С. 450-472. https://www.sibran.ru/upload/iblock/224/22431b5493 a5d71fc525247de5dc8d0e.pdf.

2. $\quad$ Пискунова Н.Н. Роль дефектов в процессах роста и растворения кристаллов (по данным атомно-силовой микроскопии) // Научные основы синтеза минералов и новых материалов (под ред. акад. А.М. Асхабова). Сыктывкар. Изд-во: Геопринт. 2012. С. 89-104.

3. Пискунова Н.Н. Исследование процессов роста и растворения кристаллов с помощью методов атомно-силовой микроскопии. Екатеринбург. Изд-во: УрО РАН. 2007. 135 с.

4. Пискунова Н.Н. Каналы дислокаций на поверхности кристаллов (по данным АСМ) // Труды Ферсмановской научной сессии ГИ КНЦ РАН. 2019. 16. С. 473-477. DOI: 10.31241/FNS.2019.16.096.

5. Портнов В.Н., Чупрунов Е.В. Кинетика и морфология дислокационного роста граней кристаллов из раствора: Учебное пособие. Нижний Новгород. Изд-во: Нижегородского гос. ун-та. 2010.131 с. http://www.unn.ru/pages/e-library/publisher_db/files/63/1.pdf.

6. Ситдикова Л.М. Особенности флюидного режима кристаллического фундамента Татарского свода // Георесурсы. 2007. Т. 263 (22). С. 26-28. https://geors.ru/media/pdf/26-28.pdf.

7. Смирнов С.З., Томас В.Г., Соколова Е.Н., Куприянов И.Н. Экспериментальное исследование герметичности включений водосодержащих силикатных расплавов при внешнем давлении $\mathrm{D}_{2} \mathrm{O}$ при $650{ }^{\circ} \mathrm{C}$ И 3 кбар // Геология и геофизика. 2011. Т. 52 (5). С. 690-703. https://www.sibran.ru/upload/iblock/a30/a300 49e166559545c6c5c93cce5c2b86.pdf.

8. Чепкая Н.А. Петрогенетическая информативность флюидных включений // Автореферат диссертации на соискание ученой степени кандидата геолого-минералогических наук. Москва. 1997. С. 14.

9. Чернов А.А. Элементарные процессы роста кристаллов из растворов // УФН. 1987. Т. 153. С. 678-681. DOI: 10.3367/UFNr.0153.198712f.0678.

10. Bodnar R.J., Vityk M.O. Interpretation of Microthermometric Data for H2O-NaCl Fluid Inclusions / In Fluid Inclusions in Minerals: Methods and Applications. Ed. De Vivo B. and Frezzoti M. L.; Virginia Tech. Blacksburg VA. 1994. P. 117-130.

11. Bodnar R.J. Reequilibration of fluid inclusions / In Fluid Inclusions: Analysis and Interpretation. Ed. I. Samson, A. Anderson, and D. Marshall, Mineral. Assoc. Canada. Short Course 32. 2003. P. 213-230. http://citeseerx.ist. psu.edu/viewdoc/download?doi=10.1.1.464.2092\&rep=rep1\&type=pdf.

12. Pecher A. Experimental decrepitation and re-equilibration of fluid inclusions in synthetic quartz // Tectonophysics. 1981. V. 78. P. 567-583. DOI 10.1016/0040-1951(81)90029-9.

13. Piskunova N.N., Rakin V.I. Statistical analysis of dynamics of elementary processes on the surface of the growing crystal (by the AFM data) // J. of Crystal Growth. 2005. V. 275 (1-2). P. 1661-1664. DOI: 10.1016/j. jcrysgro.2004.11.226.

14. Rashkovich L.N., Yoreo J.J., Orme C.A., Chernov A.A. In situ atomic force microscopy of layer-by-layer crystal growth and key growth concepts // Crystallog. Rep. 2006. V. 51 (6). P. 1063-1074. DOI: 10.1134/ S10637745060174.

15. Sterner S.M., Bodnar R.J. Synthetic fluid inclusions-Vll. Re-equilibration of fluid inclusions in quartz during laboratory-simulated metamorphic burial and uplift // Journal of Metamorphic Geology. 1989. V. 7. P. $243-260$. DOI: $10.1111 /$ j.1525-1314.1989.tb00587.x.

16. Van Driessche E.S., Ota'lora F., Sazaki G., Sleutel M., Tsukamoto K., Gavira J.A. Comparison of Different Experimental Techniques for the Measurement of Crystal Growth Kinetics// Cryst. Growth Des. 2008. V. 8 (12). P. 4316-4323. DOI: 10.1021/cg800782r.

17. Vekilov P.G. What is the Molecular-Level Role of the Solution Components in Protein Crystallization? // Crystal Growth and Design. 2007. V. 7 (11). P. 2239-2246. DOI: 10.1021/cg700989p. 